\title{
Experience of Graduate Counseling Students During COVID-19: Application for Group Counseling Training
}

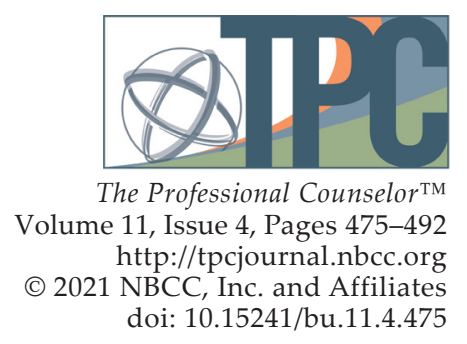

\author{
Bilal Urkmez, Chanda Pinkney, Daniel Bonnah Amparbeng, Nanang Gunawan, \\ Jennifer Ojiambo Isiko, Brandon Tomlinson, Christine Suniti Bhat
}

The COVID-19 pandemic resulted in many universities moving abruptly from face-to-face to online instruction. One group of students involved in this transition was master's-level counseling students. Their experiential group counseling training (EGCT) program started in a face-to-face format and abruptly transitioned to an online format because of COVID-19. In this phenomenological study, we examined these students' experiences of participating and leading in six face-to-face and four online EGCT groups. Two focus groups were conducted, and three major themes emerged: positive participation attributes, participation-inhibiting attributes, and suggestions for group counseling training. The findings point to additional learning and skill development through the online group experience as well as its utility as a safe space to process the novel experience brought about by COVID-19.

Keywords: experiential group counseling training, phenomenological, COVID-19, face-to-face, online format

Most of what is known about group counseling and the training of group counselors has been learned from groups that occur in face-to-face group environments (Kozlowski \& Holmes, 2014). This includes seminal works on group counseling's therapeutic factors, such as universality, altruism, instillation of hope, cohesiveness, existential factors, interpersonal learning, self-understanding, and catharsis (Yalom \& Leszcz, 2005). Researchers have found positive contributions of group therapeutic factors toward therapy outcomes (Behenck et al., 2017), and they have explored the experiences of group members in face-to-face group counseling settings, including the interpersonal and intrapersonal processes of members (Holmes \& Kozlowski, 2015; Krug, 2009; Murdock et al., 2012). By contrast, there is considerably less research on online group counseling (Kozlowski \& Holmes, 2014) or group counselors' training in online modalities (Kit et al., 2014; Kozlowski \& Holmes, 2017).

In this qualitative study, we utilized the phenomenological method to explore and compare master'slevel students' experiences of participating in and leading during six face-to-face and four online experiential group counseling training (EGCT) groups as part of an introductory group counseling course. The master's-level counseling students began their EGCT in face-to-face groups, and because of the COVID-19 pandemic, they continued to meet in four online groups after their university decided to suspend all face-to-face instruction.

\section{Experiential Groups in Counselor Education}

Group counseling training is one of the eight core areas of required training for counselors stipulated by the Council for the Accreditation of Counseling and Related Educational Programs (CACREP; 2015). In order to learn the complex group processes necessary for effective group counseling, master's-level

Bilal Urkmez, PhD, LPC, CRC, is an assistant professor at Ohio University. Chanda Pinkney, MA, CT, is a doctoral student at Ohio University. Daniel Bonnah Amparbeng, MEd, NCC, LPC, is a doctoral student at Ohio University. Nanang Gunawan, MA, is a doctoral student at Ohio University. Jennifer Ojiambo Isiko, MA, is a doctoral student at Ohio University. Brandon Tomlinson, MA, NCC, LPC, is a doctoral student at Ohio University. Christine Suniti Bhat, PhD, LPC, LSC, is a professor at Ohio University. Correspondence may be addressed to Bilal Urkmez, Patton Hall 432P, Athens, OH 45701, urkmezbi@ohio.edu. 
counseling students are required to participate in EGCT (Association for Specialists in Group Work [ASGW], 2007; CACREP, 2015). For CACREP-accredited master's programs, at least 10 clock hours of group participation during one academic semester are required (CACREP, 2015). During this experiential training, students learn to be both group counseling participants and group counseling leaders (Ieva et al., 2009) and gain valuable experience in and insight into group dynamics, group processes, and catharsis (Ohrt et al., 2014).

Master's-level counseling students "benefit a great deal when allowed to develop practical and relevant clinical skills" (Steen et al., 2014, p. 236). Experiential training in group counseling also promotes self-awareness, personal growth, and a greater understanding of vulnerability and self-disclosure in the learners (Yalom \& Leszcz, 2005). The experiential component of group counseling training provides an environment for counseling students to experience vicarious modeling, self-disclosure, validation, and genuineness from their classmates (Kiweewa et al., 2013). Finally, these experiential opportunities promote students' self-confidence (Ohrt et al., 2014; Shumaker et al., 2011; Steen et al., 2014).

\section{Online Counseling}

Barak and Grohol (2011) defined online counseling as "a mental health intervention between a patient (or a group of patients) and a therapist, using technology as the modality of communication" (p. 157). Counselors are increasingly using more digital modalities in their practice (Anthony, 2015; Richards \& Viganó, 2013), and it is being seen as a viable alternative to support clients (Hearn et al., 2017). Since the start of the COVID-19 pandemic, counselors have begun to use more online modalities to provide counseling services (Peng et al., 2020). Online counseling began to emerge as a potential solution for mental health services when providers were forced to discontinue or scale down in-person services and adjust to virtual formats during the pandemic (Békés \& Aafjes-van Doorn, 2020; Peng et al., 2020; Wind et al., 2020). Peng et al. (2020) noted the effects COVID-19 have had on the delivery of mental health services in China. They mentioned the governmental and authorities' support for preparedness and response and the multidisciplinary enhancement of remote intervention quality for clients. They also suggested that governments should integrate the mental health interventions related to COVID-19 into existing public mental health emergency preparedness and response structures.

Because of the growing importance of online counseling, it is essential to train counseling students to conduct online counseling, including online group counseling, effectively. Understanding master's students' experiences in online EGCT can help identify potential challenges they may face during their training. It is also important to explore students' experiences in face-to-face and online EGCT groups to better understand possible future training needs and help counselor educators create an educational curriculum that addresses group counseling knowledge and skills for online groups. There is currently a lack of information about how to train counseling students in the delivery of online counseling (Kozlowski \& Holmes, 2014), and specifically group counseling (Kit et al., 2014).

\section{Professional and Accreditation Bodies' Guidance on Technology}

The American Counseling Association (ACA) Code of Ethics states, "Counselors understand that the profession of counseling may no longer be limited to in-person, face-to-face interactions" (2014, p. 17). The ASGW Best Practices Guidelines require that "Group workers are aware of and responsive to technological changes as they affect society and the profession" (ASGW, 2007, p. 115, A.9). Similarly, CACREP (2015) indicates "students are to understand the impact of technology on the counseling profession" (2.F.1.j) as well as "the impact of technology on the counseling process" (2.F.5.e). CACREP 
also emphasized that students understand "ethical and culturally relevant strategies for establishing and maintaining in-person and technology-assisted relationships" (2.F.5.d). Additionally, the Association for Counselor Education and Supervision (ACES; 2018) provides guidelines for online instruction featuring descriptions regarding course quality, content, instructional support, faculty qualifications, course evaluation procedures and expected technology standards.

\section{Online Group Counseling}

Textbooks on group counseling have mainly approached EGCT in face-to-face formats (e.g., G. Corey, 2016; Yalom \& Leszcz, 2005). Given the growing interest and demand for online counseling in recent years (Holmes \& Kozlowski, 2015; Kozlowski \& Holmes, 2017), COVID-19 has highlighted the need for greater awareness and understanding of online group counseling training. However, there is limited research on online group counseling and counseling students' training in online group counseling.

Kozlowski and Holmes (2014) explored master's-level counseling students' experience in an online process group, reporting themes of participants' experiences of a linear discussion, role confusion, and feelings of being disconnected, isolated, and unheard. In 2015, Holmes and Kozlowski expanded on their work with a study on master's-level counseling students' experiences in face-to-face and online group counseling training. They found that the online group participants felt significantly less comfortable than participants in the face-to-face group. Further, participants in the study evaluated face-to-face groups as preferable for participation, social cohesion, and security (Holmes \& Kozlowski, 2015). Lopresti (2010) compared students' group therapy experiences between face-to-face and online group counseling methods using synchronous text-based software. This research involved six master's-level students engaging in an 8-week, 60-minute, weekly online group counseling session using the WebCT chat system. Results indicated that in the online format, some participants reported self-disclosure more easily, but they also shared that it was easy to hide behind the screen and to censor themselves.

\section{Effectiveness of Online Group Counseling}

Some researchers have observed the efficacy of online support groups (Darcy \& Dooley, 2007; Freeman et al., 2008; Lieberman et al., 2010; Webb et al., 2008). Haberstroh and Moyer (2012) reported that professionally moderated online support groups could supplement face-to-face counseling, especially for clients who want regular daily support during the process of recovering from self-injury. They also found that online group interaction provided clients with opportunities to engage in healthy self-expression and reduce their sense of loneliness and isolation (Haberstroh \& Moyer, 2012). King et al. (2009) examined the effectiveness of internet-based group counseling to treat clients with methadone substance abuse, reporting that internet-based group counseling could reduce resistance and nonadherence in clients. Clients expressed satisfaction with the process and reported convenience and higher levels of trust in confidentiality because they were able to participate from home.

Similarly, Gilkey et al. (2009) reported the advantages and disadvantages of synchronous videoconferencing (SVC) web-based interventions. This study involved families with children with traumatic brain injury. The results revealed that SVC had the potential for family-based therapy delivery. However, it required important factors such as client readiness to address their issues and patience with the technology's imperfections. SVC could reduce barriers to treatment with motivated families from diverse backgrounds. Nevertheless, the online group experience is vulnerable to the impact of technology glitches, privacy issues, disruptions in connectivity, and personal detachment (Amulya, 2020). In online group therapy, Weinberg (2020) identified four obstacles: managing the frame of the treatment, the disembodied environment, the question of presence, and the transparent background. 


\section{Purpose of Study and Research Questions}

In March 2020, as a result of the pandemic, our university moved most face-to-face classes to virtual environments following statewide restrictions for in-person gatherings. This sudden change led to a unique experience for first-year master's-level counseling students enrolled in an introductory group counseling course at a CACREP-accredited program in the Midwest. It was planned that students would participate in 10 face-to-face EGCT groups of 90 minutes each to fulfill the CACREP (2015) group counseling experiential training requirements. Doctoral students facilitated the first five group counseling experiences for the counselors-in-training. The plan was for two master's students to lead face-to-face groups under the supervision of doctoral students for the remaining five groups (6-10). However, the university closed for 2 weeks after Session 6 was completed. As a result, when classes resumed, they were online. EGCT Sessions 7 through 10 were conducted online using Microsoft Teams with master's students leading and doctoral students supervising. Thus, in a single semester, the master's students had the experience of participating in and leading both face-to-face and online groups. Our study was guided by the following research question: What were master students' experiences of participating and leading in both face-to-face and online EGCT groups?

\section{Methods}

\section{Research Design}

Qualitative methodology was used to explore first-year master's students' experiences of participating and leading in both face-to-face and online formats of EGCT. Our aim was to build an understanding of their experience shifting to an online modality with a specific interest in their attitudes, learning, facilitating, and adaptation to these two environments. For this purpose, a phenomenological approach was appropriate for investigating students' unique experiences in both versions of the EGCT groups. Moustakas (1994) defined phenomenology as an approach for "comprehending or having in-depth knowledge of a phenomenon or setting and ... attained by first reflecting on one's own experience" (p. 36). In a phenomenological study, the aim is to describe the essence of individuals' experiences with a certain phenomenon (Creswell \& Creswell, 2018).

\section{Participants and Procedures}

IRB approval was obtained, and purposive sampling was implemented with a recruitment email. All participants were recruited from a CACREP-accredited counseling program in the Midwest United States. Our inclusion criteria were that participants must be current master's-level counseling students and must be enrolled in a group counseling course. In addition, each participant must have experienced both participating in and leading at least one EGCT session during the prior term.

The invitation to participate in a focus group was emailed to all students enrolled in the group counseling course in the prior term. It included information about the study, addressed voluntary participation, and explained the entirely separate nature of participation in the focus group from evaluation of performance in the group class that had concluded. This recruitment email was sent out a total of three times within a 3-week period before the study was conducted.

Nine students agreed to participate in the study, and written consent forms were sent to them via email to read and review. Of the nine participants, three self-identified as male and six self-identified as female. Seven participants identified as White and two identified as "other," and the age range was 18-34 years old. Two participants were specializing in school counseling, three in clinical mental health counseling, three in clinical mental health/clinical rehabilitation counseling, and one in clinical mental health/school counseling. 
Before the focus group, prospective participants were emailed a copy of the semi-structured interview questions to alleviate any anxiety or concerns about the questions that would be asked during the study. Prospective participants were also invited to ask any questions at the start of the focus group and were then invited to provide verbal consent. To secure confidentiality, participants were assigned a code consisting of letters and numbers to protect their identity. Participants' identification codes, with corresponding names, were kept securely in the possession of the first author, Bilal Urkmez.

\section{Focus Groups}

Focus groups were used because they allow students to share their experiences with EGCT groups and compare points of view (Krueger \& Casey, 2014). Two online focus groups were held-one with five participants (one male, four females) and one with four participants (two males, two females). Participants received invitation links from the focus group facilitator via Microsoft Teams. All participants were familiar with Microsoft Teams because they had used it for their experiential groups and classes after moving to online instruction. Urkmez contacted the university's IT department regarding the protocol of recording and securing the video and audio of the focus groups on Microsoft Teams.

Our fifth and sixth authors, Jennifer Ojiambo Isiko and Brandon Tomlinson, who led and supervised the original EGCT groups, conducted the focus groups. Care was taken to ensure that master's students were not placed in a focus group led by the same doctoral student who had previously led and supervised their 10-session EGCT groups.

We used Krueger and Casey's (2014) guidelines to create a semi-structured focus group protocol. Open-ended questions were built in for the focus group leaders to use as prompts to facilitate discussion when necessary. The online focus groups lasted approximately 60 minutes. All the conversations were recorded and then transcribed verbatim by the designated focus group facilitator.

\section{Authors' Characteristics and Reflectivity}

Our research team consisted of two counselor educators with experience teaching and facilitating group counseling courses and five counselor education doctoral students. All doctoral students were part of a single cohort, and all had prior experiences facilitating group counseling. The counselor educators were Urkmez, who self-identifies as a White male, and Christine Suniti Bhat, an Asian female. The doctoral students were Chanda Pinkney, an African American female; Daniel Bonnah Amparbeng, an African male; Nanang Gunawan, an Asian male; Isiko, an African female; and Tomlinson, a White male. Before data collection, we met to discuss focus group questions, explore biases and assumptions, and assign focus group leaders for the study.

Our team used multiple strategies to establish trustworthiness. As two of the researchers taught group counseling and five of the researchers had led and supervised the EGCT groups, it was necessary to discuss possible biases before and during the data analysis process to ensure that the resulting themes and subthemes emerged from participants' responses (Bowen, 2008).

First, some of the researchers shared that they believe face-to-face group counseling is better than online group counseling because they do not personally like to take or teach online courses in their education. All research members taught, learned, and supervised EGCTs predominantly in face-to-face environments prior to the study and pandemic. Secondly, some of the researchers also mentioned their frustrations with learning and supervising online. These discussions were held to promote awareness of potential biases so as to avoid focusing on the negative experiences of the master's students. Bracketing was implemented throughout the study to reduce researchers' possible influence on participants of 
favoring face-to-face counseling environments (Chan et al., 2013). This measure helped ensure the validity of the study's data collection and analysis by having the researchers put aside any negative experiences of online learning environments during the pandemic (Chan et al., 2013). Urkmez, Pinkney, Bonnah Amparbeng, Gunawan, Isiko, and Tomlinson analyzed the data first, fulfilling investigator triangulation (Patton, 2015). This same group then met several times to discuss their analyses of the transcripts and agree upon the significant statements and themes.

\section{Experiential Group Counseling Training}

Twenty-eight first-year master's students were enrolled in an introductory group counseling course in the spring 2020 academic semester. The EGCT groups were a required adjunct to the didactic portion of the course. EGCT sessions for the master's students met weekly for 90 minutes and were set up so that the master's students were participants for Sessions 1 through 5 (led by doctoral students) and were leaders for Sessions 6 through 10 (supervised by doctoral students). All 10 sessions were planned to be face-to-face sessions. Doctoral students were enrolled in an advanced group counseling course, and their participation was a required component of the course.

During the first five sessions, doctoral students' responsibilities as leaders included facilitating meaningful interaction among the participants, promoting member-member learning, and encouraging participants to translate insights generated during the interaction into practical actions outside the group (G. Corey, 2016). For Sessions 6-10, in the role of supervisors, doctoral students' responsibilities were to mentor and monitor the master's students' group leadership skills and provide verbal feedback immediately after the session. Doctoral students also provided written feedback to both the master's students and group counseling course instructors. Additionally, the doctoral students engaged in peer supervision with each other under the tutelage of the advanced group counseling course instructor, discussing how EGCT could be supervised more effectively.

As stated previously, two master's students started to co-lead the EGCT groups during Session 6, which was conducted face-to-face. After Session 6, in-person classes were canceled by the university in response to COVID-19, so the remaining four sessions of EGCT were conducted online on Microsoft Teams. The online groups were conducted synchronously on the same day and time as the face-to-face groups had been conducted in the earlier part of the semester.

Session 7 was the first synchronous online session of the EGCT and deserves special mention. Prior to Session 7, the doctoral students received brief training on Microsoft Teams. The master's students had no previous exposure to Microsoft Teams. Thus, during Session 7, the doctoral students provided support by demonstrating how Microsoft Teams worked and processing the master's students' thoughts, feelings, and levels of wellness in relation to the sudden pandemic. Students resumed leading the online synchronous groups for Sessions 8, 9, and 10 under doctoral students' supervision.

\section{Data Analysis}

Isiko and Tomlinson led the two focus groups and transcribed the data collected from the participants who shared their experiences in the focus groups. We utilized the phenomenological data analysis method described by Moustakas (1994). Urkmez, Pinkney, Bonnah Amparbeng, Gunawan, Isiko, and Tomlinson conducted the data analysis while Bhat served as a peer debriefer because of her position of seniority in terms of expertise in not only qualitative methodology, but also group counseling research, as well as her experience of more than 15 years in teaching both master's- and doctoral-level group counseling courses at the CACREP-accredited program. Her primary role was to read the transcripts, review the raw data and analysis, and scrutinize established themes to point out discrepancies (Creswell \& Creswell, 2018). 
Our research team (except for Bhat) met to discuss our potential biases and bracket our assumptions about the phenomenon under investigation. Then, each of us independently read all transcripts multiple times to become familiar with the data. Next, we reviewed the transcripts according to the horizontalization phase of analysis (Moustakas, 1994). Moustakas defined the horizontalization phase as the part of the analysis "in which specific statements are identified in the transcripts that provide information about the experiences of the participants" (Moustakas, 1994, p. 28). During this step, we independently reviewed each transcript and identified significant statements that reflected the participants' interpretations of their experiences with the phenomenon. We identified these significant statements based on the number of times they were mentioned both within and across participants. From this point, we each independently created a list of significant statements.

Subsequently, we met to review our lists to establish coder consistency, create initial titles for the themes, and place data into thematic clusters (Moustakas, 1994). Each of our themes and related subthemes were similar in content and typically varied only in the titles used. Titles for themes and subthemes were discussed until consensus was obtained. We revisited the horizontalized statements and discussed our different perspectives. Next, we evaluated the most commonly occurring themes and created a composite summary of each theme from the participants' experiences. After these steps, we arrived at a consensus about each theme's essential meaning and decided on specific participant quotes that represented each theme.

\section{Findings}

We identified three main themes related to the participants' experiences of taking part in and leading both face-to-face and online EGCT. The three main themes were positive participation attributes, participation-inhibiting attributes, and suggestions for group counseling training.

\section{Positive Participation Attributes}

The central theme of positive participation attributes focused on exploring master's students' perceptions about what helped them actively participate in both online and face-to-face EGCT groups as a group member. Five subthemes were identified in the main theme of positive participation attributes: (a) knowing other group members, (b) physical presence, (c) comfortability of online sessions, (d) cohesiveness, and (e) leadership interventions.

\section{Knowing Other Group Members}

The EGCT group involved graduate-level counseling students who knew each other for a semester before engaging in the EGCT. Study participants shared that seeing familiar faces provided a safe and supportive environment for them to participate in both face-to-face and online group sessions as a group member. One participant noted that "a part of it helped because it was many people I had already known," and another participant stated that "it was easier to have face-to-face after we had already kind of met everybody in the semester and so I wasn't worried about confidentiality. I wasn't in this group with a whole bunch of strangers." Participants noted that knowing other group members helped them to participate actively in EGCT. They reported that having familiar faces in the group made them feel comfortable and connected, and that it helped them engage more fully during the ECGT groups.

\section{Physical Presence}

Study participants shared that group members' physical presence during the face-to-face sessions enhanced their willingness to participate. The physical presence provided access and a better ability to understand group members' content and emotion through their body language, eye contact, vocal tone, 
and other nonverbal cues during sessions. As one participant shared, "I feel so much more in touch and present with people when I can see them, but just kind of feel their physical presence rather than just watching the faces online." Furthermore, the study participants shared that being physically present during the face-to-face sessions allowed for the incorporation of more icebreaker activities by both doctoral and master's student group leaders, enhancing their participation in groups. One participant noted that "the small icebreakers, I just remember doing those at the beginning during our face-to-face sessions; those were a lot of fun."

\section{Comfortability of Online Sessions}

Participants reported that they felt comfortable engaging in online EGCT from their familiar surroundings at home. They appreciated the convenience of participating in ECGT groups from wherever they were. One participant reported that "people could be outside or eating or drinking or whatever, which I think is cool." Another participant shared that before the state-issued quarantine, they already used online technology to communicate with friends, so it was easy to use Microsoft Teams for online experiential training groups. Another participant noted:

We were doing them (EGCT) from the comfort of our own home; it just increased how comfortable you were in general. We were all at home, rocking in sweatpants and not having to worry about stuff. I feel we were in our own comfortable, safe space, and that made the online easier for me.

\section{Cohesiveness}

Participants reported they felt "anxious," "lonely," and "isolated" and experienced other difficulties during the COVID-19 pandemic. They noted that they actively engaged in online EGCT sessions because it provided them with the opportunity to connect, share, and process their thoughts and emotions. A group participant reported, "We all had to isolate. [It] made it exciting to be able to connect with everyone again, to talk about how it (COVID-19) was affecting us, to vent out our emotions and check in with others." Additionally, another participant reported:

When we started these sessions [online], it was at the beginning of these COVID-19 issues, and I was feeling more stressful, and there was nothing to do. It was so difficult to adjust to this environment, even staying at home. This was like an opportunity for me to connect with classmates in the group and [it] helped me to reflect on my anxiety and how other people were thinking around these COVID-19 issues.

As a result of the online EGCT groups, participants gained a means of personal interaction during isolation. The subthemes presented above capture the positive participation factors that helped participants to engage actively in both online and face-to-face sessions.

\section{Leadership Interventions}

Participants shared leadership interventions that helped them to participate during face-to-face and online sessions. The sudden transition to online groups due to COVID-19 was characterized by trial and error and uncertainty for everyone. Participants noted that while working with the new online EGCT group and different processes than what they experienced before COVID-19, doctoral students and master's student leaders demonstrated a sense of flexibility and adaptability to the prevailing situation and could steer the groups in the changing environment. Both the doctoral and master's student leaders were aware of the effect of COVID-19 on the participants, and they allowed the participants to get support from each other before they could get into the session plan for the 
group. One participant mentioned that "we kind of partly used that [the group] as a social support group ... and reflect on how we're feeling during social isolation." Another participant shared that "the facilitators were flexible. So, even if they had a topic or something like that, they would allow for flexibility, to check in [with participants], and be able to kind of shift focus to what we all needed."

Participants explicitly mentioned that the doctoral and master's students' leadership interventions, such as encouraging, checking in, and being present, helped them engage in the EGCT groups. Participants highlighted the strength of the group leaders' encouragement of reflection ("I appreciated that the leader really put emphasis on encouraging us to answer questions") and overall presence and attention ("[The leader] was attending our behavior and was really good with reflecting"). The participants also found the aspect of "checking in" by the leaders as something that enhanced their participation: "The leaders were always pretty quick to check in on someone if something seemed off."

Group leaders' ability to coordinate and successfully facilitate group sessions can significantly influence group outcomes (G. Corey, 2016; Gladding, 2012). Study participants shared that group facilitators demonstrated leadership skills and techniques to facilitate meaningful discussions and participation among members in both face-to-face and online sessions: "Like she [group leader] was always there to answer questions if there is silence; like she didn't want us to rely on her to do the entire conversation, so her encouragement was beneficial for me."

\section{Participation-Inhibiting Attributes}

For this main theme, we examined attributes that negatively influenced participation and leading in the online and face-to-face formats of the EGCT groups. Three subthemes were identified: (a) group dynamics, (b) challenges with online EGCT, and (c) technological obstacles for online EGCT. The most prominent subtheme that arose and spread across both group formats was that of the group dynamic. Friction within the group dynamic was one of the primary issues reported by participants. The remaining subthemes were related to challenges with online EGCT groups. These challenges include the importance of "being with" or physically present with the rest of the group, problems with missing nonverbal communication in the online meetings, difficulties navigating awkward silences and pauses in the group, and technical obstacles.

\section{Group Dynamics}

Study participants shared that the group dynamics dictated how much of a connection developed among group members and significantly influenced the progression to the working phase in the groups. In the words of one participant, "I feel like that was definitely something with our group dynamic. ... There was definitely still good conversations, but I think that impacted it."

Some participants reported their initial concerns about fostering rapport with group mates chosen randomly for them. Participants expressed thoughts that personalities did not mesh well in their group and that there were issues of building good rapport. Some participants indicated that having a reserved personality made it hard to participate: "For me, it was more about a personal thing because I am an introverted personality, so I find it difficult to talk in groups anyway, so that's what hindered my participation sometimes." Another participant stated: "I felt like the others protect themselves by not talking, so why should I open myself and put myself into risk? I thought about that."

\section{Challenges With Online EGCT}

Participants in this study emphasized that one of the main difficulties of the online EGCT experience that affected their participation and leadership negatively was missing body language and physical 
cues. Participants shared that they could use nonverbal cues and body language to know when it was a good time to speak without interrupting other group members during the face-to-face ECGT. Because these were missing in online EGCT, the students did not have immediate awareness to participate in group conversation without interrupting other group members. For example, one participant noted the difficulties of "just not being able to read body language as well and not being able to see everyone at once." As a result of these online environment limitations, study participants indicated they had a sense of "stepping on toes" while trying to participate in online EGCT: "I think that one of the biggest challenges with doing it [EGCT] online is that you want to be respectful and make sure that you are not gonna talk over somebody else."

Kozlowski and Holmes (2014) previously noted that the unfamiliar environment of online counseling, the time delay because of technology, and the inability to utilize group members' body language can all create a one-dimensional or "linear" experience in online group counseling environments. These factors appeared to hinder the natural growth and development of the EGCT groups in our study as well. In an effort to reduce the perception of being rude, there were times of awkward silence as participants avoided constant interruptions during the sessions; this difficulty gave the feeling of a linear environment.

One other factor the participants noted in the online format more so than the in-person group was what students described as an awkward silence. This occurrence serves as a subtheme of missed physical cues because the participants noted that the lack of said cues complicated determining when to speak and when to wait: "Online, the silence almost felt like it was much longer than what it really would have been if it was face-to-face." Another participant stated that they "feel pretty comfortable with silences, but it's a lot harder to gauge that when it's online." This issue presented itself in several circumstances, though one group did attempt to figure out a solution, per the report of one participant: "For our group ... to help with people talking over each other, we had people type in a smiley face in the chat when they wanted to share."

Notably, participants in this study also mentioned that there was some physical presence that they could not describe but found to be relevant to them in their connection with the group. Although students were unable to identify it precisely, several study participants agreed on its importance. One participant said that they "enjoy the voice and the video, but I feel like when we are talking, especially in a group dynamic and group processes, especially to grasp something important, I really need to be with this person in a physical space."

The participants emphasized the importance of physical presence, from the ability to see and greet one another to having space to do activities that got them up and moving. Many participants mentioned some intangible quality they could not name but that was missing when the groups convened electronically instead of in person. A participant shared that "you can observe the body language-what is happening in the group actually, but in online sessions, it's like you don't know, you are just talking."

As noted in other sections, the group members appreciated the space for doing activities together when they were in person. Master's student group leaders reported that they felt anxious when facilitating icebreaker activities in their online EGCT sessions because of the missing physical presence and noted the loss of face-to-face icebreakers. Study participants lamented that the online format did not allow for these bonding and icebreaking exercises, which when utilized in the usual face-to face format tended to put them in a position to feel better equipped to share with their group members, 
almost like a metaphorical entryway to the group process: "Some of the exercises are not possible to execute [online] because we were doing some physical things in our group, like throwing balls to each other and stuff." Without these social warm-ups, the group flow and process suffered; according to those in the focus group, leaders needed more assistance to run activities in online EGCT sessions. One participant added a similar sentiment: "How do we lead a group online with proximity activities or icebreakers we would use? We can't really do [that] because of the virtual interaction, [it] can't work."

Overall, the online EGCT environment limited the interpersonal relationships of the EGCT members and group leaders. Group members could not use their nonverbal communication skills or participate in physical group activities. Lastly, online EGCT appears to provide added pressure on group leaders to keep members engaged during the session. Master's students had to choose topics where all members felt comfortable enough to participate with minimal encouragement, which was a challenge.

\section{Technological Obstacles for Online EGCT}

Participants reported some technological difficulties that inhibited their ability to participate and lead the online EGCT sessions. Some participants noted that when participants turned off their cameras, it exacerbated disengagement levels within the group and hampered group dynamics. Some speculated that technical difficulties might be an excuse to disengage from the group: "Like in online, I can be mute, I can turn off my camera, I can not talk, and I can accuse the technology for that." This capacity to disengage negatively impacted the group for several of the focus group participants, who noted that they felt this closed off the group and circumvented the ability to engage with all members of the group.

The limitations of the university-sanctioned online platform used for the EGCT groups, Microsoft Teams, adversely affected engagement during the online sessions as it only allowed four members (at the time of the online EGCT sessions) to be seen on the screen at a time. As one participant stated, "I cannot see all the group members ... my attention is not with all members. This was difficult. It was difficult to lead the group." Several group members were vociferous in their dislike for this limitation of the platform. Further, internet connectivity issues were problematic: "Sometimes like a group member would disconnect [because of technology problems], and there would be several minutes before they could come back." These types of interruptions were frustrating to all group members and group leaders. Master's student group leaders had a difficult time leading with interruptions.

One focus group participant noted, and others agreed, that it was challenging to learn how to lead a group online because they were missing so many elements of the in-person process of leading a group, and they did not have previous group leadership experience in an online environment. A participant shared that "it's hard [leading group online]. It's maybe harder for leaders because they cannot observe what's going on ... like body language."

\section{Suggestions for Group Counseling Training}

Participants were invited to share their concerns and ways to develop and improve face-to-face and online EGCT group experiences. Three subthemes were identified: (a) software issues and training, (b) identified group topics, and (c) preferred EGCT environment.

\section{Software Issues and Training}

Participants shared common concerns about the software for their online experiential training groups. Specifically, they found Microsoft Teams' display of only four people at one time prevented them from seeing all group members on the screen. Members who were not speaking were displayed at the bottom of the computer screen with their profile picture or initials, which was not conducive 
to interaction. One participant suggested that they should "probably just use Zoom instead ... I like Zoom better, seriously, because I can see absolutely everyone." Another participant agreed, "But for the reason, at least, in Zoom, I can see everyone's faces, not, um, not just four."

Another participant similarly emphasized the importance of seeing everyone on one screen during their meeting: "If you don't see the faces [at one time], you're just clueless. I mean, have to, like, awkwardly check in with this person all the time." Participants also brought another suggestion about training on leading online experiential training groups. Participants shared their anxiety about leading groups using online software because it is a new and unique experience. Because of the sudden onset of COVID-19, the students did not have a chance to get training on how to lead online experiential training groups. A participant mentioned that having training where students could learn how to facilitate online groups before leading weekly sessions would help alleviate anxiety and build competence: "Perhaps allowing a small period where everyone kind of gets adjusted to it and becomes more familiar with it might help facilitate [online] group sessions better."

\section{Identified Group Topics}

Another suggestion by participants regarding their EGCT experience was using one selected topic for each group. For example, a participant shared: "I think part of what was hard about this that might be something to change is, like having the group just be all over the place in terms of topics from week to week." Another participant added: "If the group was more, like, a little bit more specific and clearer about like, the goal, or something like that, that might be-might help it flow a little bit better." Some participants also suggested allowing students to select which group they wanted to attend, instead of having groups pre-assigned to them. In other words, participants preferred to join a specific group based on their interests. A participant mentioned: "I think that would be like a really good option to give like a list of ten types of groups or topics in the groups." Another participant similarly suggested "giving an opportunity to all students to choose one group. For example, like the one group would work specifically on self-esteem problems or the other one would work on grief problems."

Some participants noted that they felt there was a lack of purpose for the group, indicating that they were not sure of the group's goals or objectives and that this hindered their ability to participate fully. Some also shared having confusion about their role and the boundaries of the group and what they could or could not share. One participant noted: "In the first session when we were trying to set up our goals, it was difficult for us to find what the goals will be as a group leader candidate, or as a person." The focus group participants suggested giving more concrete topics overall for the EGCT group to understand better how to participate. This notion spanned across the online and face-to-face format as a more general recommendation.

\section{Preferred Training Environment}

Lastly, participants were asked about their preference for participation in a face-to-face or online EGCT experience, if given a choice. Even though participants reported a reasonably good experience with online EGCT groups, such as comfortability and cohesiveness, most of the participants voiced a preference for face-to-face sessions if they had to do the group counseling training over again. One participant stated: "Ultimately, face-to-face will probably still be better." Another participant added: "Face-to-face for sure. I just think as like a profession, we all enjoy working with people. We would prefer to work with someone in person." Similarly, another participant mentioned: "I would definitely choose face-to-face, but I was thankful that we had the opportunity to do it online." 
Asking the participants about their preferred experiential training group environment garnered the most reaction during the interviews. Most of the participants shared that they preferred face-toface groups. Even though participants had personal connections in an online setting, they wanted to have face-to-face meetings to interact better. One participant mentioned that "we are doing online sessions right now. I wish that I [could] continue to do the group lab and connect with the group members, but if I have the opportunity to take face-to-face, absolutely, I would do that." Lastly, another participant added: "Absolutely, it's face-to-face, but if we are in a situation like this, COVID-19 issues, sometimes the online sessions can be helpful."

Participants offered their perspectives on learning group counseling skills during the global COVID-19 pandemic. Despite the unprecedented circumstances, the students persevered and completed the course. Group leaders and professors encouraged the group members to participate to the best of their abilities. The concerns and suggestions shared in these focus groups could help counselor educators plan and develop for EGCT in both online and face-to-face formats.

\section{Discussion}

This study investigated the experiences of master's students in an online and face-to-face EGCT group. EGCT is an essential aspect of novice counselors' preparation and is required by CACREP (2015) standards. In this study, participants identified positive factors related to their EGCT group participation, such as knowing other group members, group leadership skills, physical presence, and connection with other group members. They also reported participation-inhibiting factors such as the complexities of group dynamics, missing physical cues, and technological challenges. Our research findings are similar to Kozlowski and Holmes's (2014) study on online group counseling training. Their participants reported problems with the group feeling artificial, lacking attending skills, and difficulties with achieving cohesion and connectedness.

In the current study, course instructors and student leaders did not have control over the choice of an online platform. The limitations of Microsoft Teams, which at the time of the online EGCT sessions only allowed four participants to be visible on the screen at one time, added to difficulties with engaging and feeling connected. For participants to remain engaged, leaders and instructors should have access to online platforms that allow students to see all group members simultaneously on the screen. Setting ground rules requiring that cameras remain on during sessions and utilizing the chat feature or the hand-raising feature to facilitate discussions would also help create and maintain a sense of connection. Outlining contingency plans such as the alternatives for not being able to join the group with the camera on are important for successful group outcomes.

Participants in this study appreciated the convenience of participating in online ECGT groups. This is similar to the findings of King et al. (2009) about the convenience of access to online group counseling. In the same study by King et al. (2009), the participants shared that online counseling sessions allowed them to participate from the comfort of their homes, thus improving both convenience and privacy. One of the difficulties participants reported was that of awkward silence. This experience, coupled with interruptions ("stepping on toes"), resulted in students finding that the experience online was more linear and less organic compared to face-to-face interactions. These findings are similar to those of Kozlowski and Holmes (2014). Yalom and Leszcz (2005) noted that the group leader's role is to design the group's path, get it going, and keep it functional to achieve effectiveness. Presence, self-confidence, 
the courage to take risks, belief in the group process, inventiveness, and creativity are essential leadership traits in leading groups (G. Corey, 2016). However, these traits are for in-person groups. It is possible that effectively leading online groups requires other skills that have not yet been identified. The sudden change to online training in this instance did not allow for a planful design. It is necessary for group leaders to possess specific group leadership skills and appropriately perform them to help group members participate in groups (M. S. Corey et al., 2018). However, participants appreciated that the doctoral and master's student leaders demonstrated flexibility, allowing for additional time to check in with group members and process their experiences and emotions related to the pandemic.

One interesting finding related to how COVID-19 impacted participants' experiences in the ECGT groups was that group participants actively engaged in the online sessions when they were allowed to process their anxiety and stress due to COVID-19, as it served as a support group. This result is dissimilar to findings of previous studies in which participants felt unsafe during online group sessions and being on online platforms impeded participants' emotional connection and trust levels (Fletcher-Tomenius \& Vossler, 2009; Haberstroh et al., 2007; Kozlowski \& Holmes, 2014).

Bellafiore et al. (2003) emphasized online group leaders' roles as "shaping the group" and "setting the tone." They also expressed that "establishing and maintaining a leadership style is important in keeping the group going" (p. 211). In the current study, first-year master's students, many of whom were participating in or leading groups for the first time, had the unexpected and sudden additional layer of learning how to lead online. Further, the abrupt transition from face-to-face to online groups because of COVID-19 did not allow for extensive instructor planning and preparation. Leading groups online was challenging and anxiety-provoking for members, as they lacked experience and were unsure how to proceed. Master's students need additional training on facilitating online groups, establishing a leadership style, and managing silence. This information corresponds with Cárdenas et al.'s (2008) findings that master's-level counseling students felt more confident to provide online counseling services after training.

\section{Implications}

Although the findings from this study are not generalizable, there may be implications for designing and leading EGCT groups that merit consideration based on the experience of the counselor trainees described in this study. Part of the group design entailed assigning different topics to focus on for each session. The rationale for having different topics for each session should be clearly explained to the participants. Any questions regarding the identified topics should be addressed early to enhance the group facilitation process for both leaders and participants. Additionally, group leaders or course instructors need to explain roles clearly, and group members should understand the group's boundaries and how they fit with their didactic course.

With online EGCT groups, it is essential to consider how participation is influenced by a lack of natural communication signals, such as body language and physical presence. Counselor educators and EGCT student leaders need to establish ground rules about online group interactions such as having all cameras remain on during sessions, having a private and quiet space from which to participate, and minimizing distractions from pets or relatives, all of which are necessary for successful groups. Further, utilizing technology that allows all members to be seen on the screen may help build connection and cohesiveness. Utilizing methods such as using the chat to insert a symbol or using the hand-raising icon can also help facilitate participation. 
Overall, students reported feeling unprepared to lead online counseling groups. However, as counselor educators, we are responsible for preparing our students to engage in online counseling successfully, especially as the COVID-19 pandemic continues into its second year and will continue to affect how much virtual counseling will take place in the future. The recent normalization of online counseling (individual and group) may persuade educators and counselors to "increase their skills in terms of development, comfortability, and flexibility in the online environment" (International OCD Foundation, 2020, p. 1). Therefore, counselor educators should cover online-specific facilitation skills in their training programs.

\section{Limitations and Future Research Directions}

This study was the first step in attempting to understand and describe master's-level students' experiences of participating and leading in both face-to-face and online formats of EGCT. As with all research, limitations should be considered in interpreting the findings. Further, some of the limitations point to potential research directions.

COVID-19 created a situation where the transition from face-to-face to online formats was compulsory. It is therefore not clear what the experience would have been like if the transition was planned and did not have a situation like COVID-19 in the background pushing the transition, or if the group had been entirely online. Because of unplanned adjustment, course instructors and student leaders did not have control over the choice of an online platform. Outlining contingency plans, such as alternatives when a group member cannot join the group with their camera on, are essential for successful group outcomes, and a lack of familiarity with online platforms may have prevented instructors and student leaders from providing these contingencies and therefore impacted the experience for students.

Further, the EGCT groups were conducted with master's-level students, and participants already had preexisting relationships with each other. This may have contributed to their strong support of face-to-face groups over online groups. In future research, studies with participants who do not already know each other may help us assess the appeal of online groups to participants. Further, researchers in the future may wish to examine the efficacy of online group counseling training for counseling students compared to in-person group training by comparing two equivalent experiential groups.

The current study recruited master's-level counseling students from a CACREP-accredited counseling program in the Midwest United States; thus, results cannot be generalized to other institutions. The sample size was small in the current study. Therefore, we caution against generalizing our findings. During the focus groups, participants shared some apprehension about how much information to disclose in group counseling, and they verbalized some confusion on group purpose, direction, or goals. For many, these EGCT groups were the students' first experience in group counseling training, and this could contribute to them questioning if their feelings and experiences were appropriate (Ohrt et al., 2014).

There are methodological considerations to improve future studies. Focus groups were conducted to collect the data from the participants. In-depth individual interviews would enhance a deeper conversation in understating and reflecting on the challenges and needs of master's-level students. Participants may have censored some of their true feelings, as they were aware that their group leaders were also part of the research team, even though they did not run the focus groups. We acknowledge that the students knowing each other from previous classes may have influenced how much they 
shared in groups. Participants in this study expressed comfort with knowing each other from a previous semester. However, it is also possible that students may have disclosed minimal personal information so as not to effect public perception of themselves or effect future professional relationships.

Another area to expand on would be investigating counselors' self-efficacy while facilitating online counseling groups. For example, exploring positive participation attributes that increase online groups' participation from the leader's perspective could be useful. This may allow researchers and practitioners to identify how group counseling can best be leveraged in an online environment.

\section{Conclusion}

The purpose of this study was to explore and compare first-year master's-level counseling students' experiences of participating and leading in both face-to-face and online formats of EGCT. In summary, students considered that the online format was challenging because it added a layer of learning to their fledgling group work skills beyond the face-to-face setting. Technological barriers that were outside the control of participants inhibited their participation, but on the other hand, the online groups served as a safe and supportive space for students to alleviate their stress and loneliness due to COVID-19. Regardless of the teaching environment, thoughtful and well-planned EGCT groups are essential for student development in this area, and skilled group leaders can manage group dynamics and model group counseling skills. COVID-19 has necessitated a focus on teletherapy and online counseling. The group counseling profession should be proactive in addressing this training need, as conducting online group counseling sessions is likely to continue to be a much-needed skill in a post-pandemic world.

\section{Conflict of Interest and Funding Disclosure}

The authors reported no conflict of interest or funding contributions for the development of this manuscript.

\section{References}

American Counseling Association. (2014). ACA code of ethics. https://www.counseling.org/docs/default-source/ default-document-library/2014-code-of-ethics-finaladdress.pdf?sfvrsn=96b532c 2

Amulya, D. S. L. (2020). An experiment with online group counseling during COVID 19. In L. S. S. Manickam (Ed.), COVID-19 pandemic: Challenges and responses of psychologists from India (pp. 182-197).

Anthony, K. (2015). Training therapists to work effectively online and offline within digital culture. British Journal of Guidance \& Counselling, 43(1), 36-42. https://doi.org/10.1080/03069885.2014.924617

Association for Counselor Education and Supervision. (2018). ACES guidelines for online learning - 2017. https://acesonline.net/knowledge-base/aces-guidelines-for-online-learning-2017-2

Association for Specialists in Group Work. (2007). Association for Specialists in Group Work: Best practice guidelines. https://www.researchgate.net/publication/247784312 Association for Specialists in Group Work Best Practice Guidelines 2007 Revisions

Barak, A., \& Grohol, J. M. (2011). Current and future trends in internet-supported mental health interventions. Journal of Technology in Human Services, 29(3),155-196. https://doi.org/10.1080/15228835.2011.616939 
The Professional Counselor I Volume 11, Issue 4

Behenck, A., Wesner, A. C., Finkler, D., \& Heldt, E. (2017). Contribution of group therapeutic factors to the outcome of cognitive-behavioral therapy for patients with panic disorder. Archives of Psychiatric Nursing, 31(2), 142-146. https://doi.org/10.1016/j.apnu.2016.09.001

Békés, V., \& Aafjes-van Doorn, K. (2020). Psychotherapists' attitudes toward online therapy during the COVID-19 pandemic. Journal of Psychotherapy Integration, 30(2), 238-247. https://doi.org/10.1037/int0000214

Bellafiore, D. R., Colon, Y., \& Rosenberg, P. (2003). Online counseling groups. In R. Kraus, J. Zack, \& G. Stricker (Eds.), Online counseling: A handbook for mental health professionals (pp. 197-216). Academic Press.

Bowen, G. A. (2008). Naturalistic inquiry and the saturation concept: A research note. Qualitative Research, 8(1), 137-152. https://doi.org/10.1177/1468794107085301

Burlingame, G. M., McClendon, D. T., \& Yang, C. (2019). Cohesion in group therapy. In J. C. Norcross \& M. J. Lambert (Eds.), Psychotherapy relationships that work: Evidence-based therapist contributions (pp. 205-244). Oxford University Press.

Cárdenas, G., Serrano, B., Flores, L. A., \& De la Rosa, A. (2008). Etherapy: A training program for development of clinical skills in distance psychotherapy. Journal of Technology in Human Services, 26(2-4), 470-483. https://doi.org/10.1080/15228830802102180

Chan, Z. C., Fung, Y., \& Chien, W. T. (2013). Bracketing in phenomenology: Only undertaken in the data collection and analysis process. The Qualitative Report, 18(30), 1-9. https://doi.org/10.46743/2160-3715/2013.1486

Corey, G. (2016). Theory and practice of group counseling (9th ed.). Cengage.

Corey, M. S., Corey, G., \& Corey, C. (2018). Groups: Process and practice (10th ed.). Cengage.

Council for the Accreditation of Counseling and Related Educational Programs. (2015). CACREP 2016 standards. http://www.cacrep.org/wp-content/uploads/2017/08/2016-Standards-with-citations.pdf

Creswell, J. W., \& Creswell, J. D. (2018). Research design: Qualitative, quantitative, and mixed methods approaches (5th ed.). SAGE.

Darcy, A. M., \& Dooley, B. (2007). A clinical profile of participants in an online support group. European Eating Disorders Review, 15(3), 185-195. https://doi.org/10.1002/erv.775

Fletcher-Tomenius, L., \& Vossler, A. (2009). Trust in online therapeutic relationships: The therapist's experience. Counselling Psychology Review, 24(2), 24-33.

Freeman, E., Barker, C., \& Pistrang, N. (2008). Outcome of an online mutual support group for college students with psychological problems. Cyberpsychology \& Behavior, 11(5), 591-593. https://doi.org/10.1089/cpb.2007.0133

Gilkey, S. L., Carey, J., \& Wade, S. L. (2009). Families in crisis: Considerations for the use of web-based treatment models in family therapy. Families in Society, 90(1), 37-45. https://doi.org/10.1606/1044-3894.3843

Gladding, S. T. (2012). Groups: A counseling specialty (6th ed.). Pearson.

Haberstroh, S., Duffey, T., Evans, M. P., Gee, R., \& Trepal, H. (2007). The experience of online counseling. Journal of Mental Health Counseling, 29(3), 269-282. https://doi.org/10.17744/mehc.29.3.j344651261w357v2

Haberstroh, S., \& Moyer, M. (2012). Exploring an online self-injury support group: Perspectives from group members. The Journal for Specialists in Group Work, 37(2), 113-132. https://doi.org/10.1080/01933922.2011.646088

Hearn, C. S., Donovan, C. L., Spence, S. H., \& March, S. (2017). A worrying trend in social anxiety: To what degree are worry and its cognitive factors associated with youth social anxiety disorder? Journal of Affective Disorders, 208, 33-40. https://doi.org/10.1016/j.jad.2016.09.052

Holmes, C. M., \& Kozlowski, K. A. (2015). A preliminary comparison of online and face-to-face process groups. Journal of Technology in Human Services, 33(3), 241-262. https://doi.org/10.1080/15228835.2015.1038376

Ieva, K. P., Ohrt, J. H., Swank, J. M., \& Young, T. (2009). The impact of experiential groups on master students' counselor and personal development: A qualitative investigation. The Journal for Specialists in Group Work, 3(4), 351-368. https://doi.org/10.1080/01933920903219078

International OCD Foundation. (2020, July 15). Teletherapy in the time of COVID-19. https://iocdf.org/covid19/ teletherapy-in-the-time-of-covid-19

King, V. L., Stoller, K. B., Kidorf, M., Kindbom, K., Hursh, S., Brady, T., \& Brooner, R. K. (2009). Assessing the effectiveness of an Internet-based videoconferencing platform for delivering intensified substance abuse counseling. Journal of Substance Abuse Treatment, 36(3), 331-338.

https://doi.org/10.1016/j.jsat.2008.06.011 
Kit, P. L., Wong, S. S., D’Rozario, V., \& Teo, C. T. (2014). Exploratory findings on novice group counselors' initial co-facilitating experiences in in-class support groups with adjunct online support groups. The Journal for Specialists in Group Work, 39(4), 316-344. https://doi.org/10.1080/01933922.2014.954737

Kiweewa, J., Gilbride, D., Luke, M., \& Seward, D. (2013). Endorsement of growth factors in experiential training groups. The Journal for Specialists in Group Work, 38(1), 68-93. https://doi.org/10.1080/01933922.2012.745914

Kozlowski, K. A., \& Holmes, C. M. (2014). Experiences in online process groups: A qualitative study. The Journal for Specialists in Group Work, 39(4), 276-300. https://doi.org/10.1080/01933922.2014.948235

Kozlowski, K. A., \& Holmes, C. M. (2017). Teaching online group counseling skills in an on-campus group counseling course. Journal of Counselor Preparation and Supervision, 9(1).

Krueger, R. A., \& Casey, M. (2014). Focus groups: A practical guide for applied research (5th ed.). SAGE.

Krug, O. T. (2009). James Bugental and Irvin Yalom: Two masters of existential therapy cultivate presence in the therapeutic encounter. Journal of Humanistic Psychology, 49(3), 329-354. https://doi.org/10.1177/0022167809334001

Lieberman, M., Winzelberg, A., Golant, M., Wakahiro, M., DiMinno, M., Aminoff, M., \& Christine, C. (2010). Online support groups for Parkinson's patients: A pilot study of effectiveness. Social Work Health Care, 42(2), 23-38. https://doi.org/10.1300/J010v42n02_02

Lopresti, J. M. (2010). The process and experience of online group counseling for masters-level counseling students (Order No. 3451084). Available from ProQuest Dissertations \& Theses A\&I. (862058819).

Moustakas, C. (1994). Phenomenological research methods. SAGE.

Murdock, J., Williams, A., Becker, K., Bruce, M. A., \& Young, S. (2012). Online versus on-campus: A comparison study of counseling skills courses. The Journal of Human Resource and Adult Learning, 8(1), 105-118.

Ohrt, J. H., Prochenko, Y., Stulmaker, H., Huffman, D., Fernando, D., \& Swan, K. (2014). An exploration of group and member development in experiential groups. The Journal for Specialists in Group Work, 39(3), 212-235. https://doi.org/10.1080/01933922.2014.919047

Patton, M. Q. (2015). Qualitative research \& evaluation methods: Integrating theory and practice (4th ed.). SAGE.

Peng, D., Wang, Z., \& Xu, Y. (2020). Challenges and opportunities in mental health services during the COVID-19 pandemic. General Psychiatry, 33(5). https://doi.org/10.1136/gpsych-2020-100275

Richards, D., \& Viganó, N. (2013). Online counseling: A narrative and critical review of the literature. Journal of Clinical Psychology, 69(9), 994-1011. https://doi.org/10.1002/jclp.21974

Shumaker, D., Ortiz, C., \& Brenninkmeyer, L. (2011). Revisiting experiential group training in counselor education: A survey of master's-level programs. The Journal for Specialists in Group Work, 36(2), 111-128. https://doi.org/10.1080/01933922.2011.562742

Steen, S., Vasserman-Stokes, E., \& Vannatta, R. (2014). Group cohesion in experiential growth groups. The Journal for Specialists in Group Work, 39(3), 236-256. https://doi.org/10.1080/01933922.2014.924343

Webb, M., Burns, J., \& Collin, P. (2008). Providing online support for young people with mental health difficulties: Challenges and opportunities explored. Early Intervention in Psychiatry, 2(2), 108-113. https://doi.org/10.1111/j.1751-7893.2008.00066.x

Weinberg, H. (2020). Online group psychotherapy: Challenges and possibilities during COVID-19-A practice review. Group Dynamics: Theory, Research, and Practice, 24(3), 201-211. https://doi.org/10.1037/gdn0000140

Wind, T. R., Rijkeboer, M., Andersson, G., \& Riper, H. (2020). The COVID-19 pandemic: The 'black swan' for mental health care and a turning point for e-health. Internet Interventions, 20. https://doi.org/10.1016/j.invent.2020.100317

Yalom, I. D., \& Leszcz, M. (2005). The theory and practice of group psychotherapy (5th ed.). Basic Books. 